\title{
Une approche interculturelle du roman Vendredi ou la vie sauvage
}

\author{
Juan C. Jiménez Murillo ${ }^{1}$
}

Universidad Nacional, Costa Rica

\section{RESUMEN}

El presente análisis basado en la novela de aventuras Vendredi ou la vie sauvage del escritor francés Michel Tournier pretende dilucidar la dinámica del enfoque intercultural a través de los personajes Viernes y Robinson Crusoe, dos seres culturalmente diferentes que logran comprenderse y tolerarse mutuamente. Hechos culturales como la imposibilidad del individuo de vivir apartado de la sociedad, el etnocentrismo, el intercambio intercultural, la ignorancia como causa de estereotipos y la tolerancia como vía hacia la comprensión, han sido abordados según tres categorías de análisis: la función de los personajes, sus acciones y su visión del mundoque les rodea.

\section{RESUMÉ}

Cette analyse, basée dans le roman d'aventures Vendredi ou la vie sauvage de l'écrivain français Michel Tournier, prétend élucider la dynamique de l'approche interculturelle à travers les personnages Vendredi et Robinson Crusoé, deux êtres qui malgré leurs différences culturelles arrivent à une compréhension mutuelle. Des faits culturels tels que l'impossibilité pour l'individu de vivre isolé, l'ethnocentrisme, l'échange interculturelle, l'ignorance comme source de stéréotypes et la tolérance comme voie à la compréhension de l'autre ont été abordés d'après trois catégories d'analyse : la fonction des personnages, leurs actions et leur vison du monde.

Correo electrónico: jcjm79@costarricense.cr 
Palabras clave: francés, enseñanza del francés, enfoque intercultural de la literatura, literatura francesa.

Mots-clés : français, enseignement du français, approche interculturelle de la littérature, littérature française.

Relisant son roman, je ne pouvais pas en effet oublier mes années d'études au musée de l'Homme. Là, j'avais appris qu'il n'y a pas de "sauvages ", mais seulement des hommes relevant d'une civilisation différente de la nôtre et que nous avions grand intérêt à étudier. L'attitude de Robinson à l'égard de Vendredi manifestait le racisme le plus ingénu et une méconnaissance de son propre intérêt. Car pour vivre sur une île déserte du Pacifique ne vaut-il pas mieux se mettre à l'école d'un indigène rompu à toutes les techniques adaptées à ce milieu particulier que de s'acharner à plaquer sur elle un mode de vie purement anglais ?

Michel Tournier

Le roman d'aventures Vendredi ou la vie sauvage de l'écrivain français Michel Tournier, permet l'observation de certaines situations susceptibles d'être focalisées dès l'angle interculturel et qui conduisent à élucider la problématique de l'altérité en tant que ligne directrice de la compréhension et de la tolérance entre cultures différentes.

\section{L'impossibilité pour l'homme de vivre isolé}

\section{À force de réfléchir, il finit par comprendre ce qui lui arrivait. C'était parce qu'il était seul...}

Tous les hommes, obéissant à un instinct inné, éprouvent la nécessité de communiquer avec ceux qui appartiennent à leur espèce.

\footnotetext{
${ }^{2}$ Paroles de Michel Toumier lorsqu'il lisait Robinson Crusoé de Daniel Defoe, œuvre originale qui lui a servi d'inspiration pour écrire, après, ses romans Vendredi ou les limbes du Pacifique et Vendredi ou la vie sauvage.
} 
Cette communication constitue un espace où ils partagent et connaissent tout ce qui leur est commun et qui contribue à leur unifier ainsi que ce qui les distingue et qui tend à les opposer.

Cette situation se fait évidente chez Robinson Crusoé, le seul survivant de son espèce sur une île inhabitée du Pacifique. Il constitue un exemple clair du danger qui entraîne la solitude et de la nécessité pour l'individu à interagir avec l'autre. Robinson, en tant qu'individu appartenant à une société donnée, avait souffert un processus de séparation de celle-ci. Cette séparation avait nuit profondément sa personne car il avait perdu le contact avec la collectivité, et il n'y avait aucun sujet similaire à lui avec qui il pourrait échanger son avis. Robinson commençait à connaître de plus en plus les conséquences de cette rupture. Il était très difficile pour lui de s' habituer à vivre sur cette île. M. Tournier l'écrit bien en se référant à l'état de solitude que vivait son héros : "c'est très difficile de rester un homme quand personne n'est là pour vous aider!»

\section{Le regard ethnocentriste de Robinson}

C'est surtout aux non francophones qui doit s'adresser le message de la francophonie, car il n'y a pas de démocratie sans diversité.

Si tout le monde porte le même costume, parle la même langue, observe les mêmes traditions, nous risquons d'établir un régime mondial de type fasciste.

Boutros Boutros-Ghali, secrétaire à la francophonie

Tous les individus, en tant qu'êtres faisant partie d'une société donnée, manifestent la tendance à privilégier le groupe social auquel ils appartiennent, par-dessus tout autre, et à en faire le seul modèle de référence pour concevoir la réalité qui les entoure. Lorsque Robinson se trouve tout seul sur l'île, il ne trouve pas de manifestations lui rappelant sa culture, c'est cette condition qui ne lui permet pas de s'y 
sentirà l'aise. Ce sentiment d'appartenance culturelle était si nécessaire pour lui qu'il décide de construire une reproduction de celle-ci. C'est ainsi qu' après un certain temps, il commence à civiliser l'île Speranza en prenant comme modèle sa propre société, que, d'après son point de vue, il considérait la meilleure. Cette attitude chez Robinson, est définie par Lévi-Strauss comme « une sorte de foyer virtuel auquel il est indispensable de se rapporter pour expliquer un certain nombre de choses ${ }^{3}$.

À partir de ce moment-là, Robinson n'arrête pas d'organiser cette île d'après sa vision du monde. Il réussit, ainsi, à faire de cet espace géographique une réplique de la structure sociale de l'Angleterre à la deuxième moitié du XVIII ${ }^{e}$ siècle, il essaie d'établir son propre modèle culturel : il fait ondoyer le drapeau anglais comme signe de son nationalisme, de l'appartenance à une culture dont il se sentait orgueilleux, il y cultive toute sorte de graines comestibles connues en Europe, il domestique des animaux sauvages, etc. Son temps, il l'organise à la manière anglaise en consacrant chaque période de la journée à de différentes activités : faire sa toilette, lire la Bible, cultiver la terre, se nourrir, prendre une sieste, etc. Tout était organisé avec une rigueur telle que même les tortues y étaient soigneusement enregistrées.

\section{Toute culture tend à se naturaliser}

Parallèlement au désir d'instaurer une reproduction de l'Angleterre sur l'île, Robinson exprime une impossibilité à percevoir le système des valeurs dans lequel s'inscrivait sa propre culture. Il s'agit d'une incapacité de prendre conscience, pour lui-même, de ce qu'il était, de connaître la dimension dans laquelle s'établissait sa pensée. D'après Robinson, sa culture étant conçue comme universelle, elle devrait être, pour les autres, le seul modèle à suivre. Ce comportement se présente souvent dans tout individu du fait que la

\footnotetext{
${ }^{3}$ C. Lévi-Strauss, L'identité (séminaire dirigé par Lévi-Strauss), cité par Abdallah-Pretceille, M. Vers une pédagogie interculturelle (Paris: Anthropos, 1995) 21.
}

126 
culture maternelle manifeste toujours la tendance à se naturaliser. Étant donné que les faits culturels qui la composent deviennent si ordinaires, à cause de l'habitude, ils sont perçus par les individus qu'y sont immergés comme relevant de l'ordre naturel :

...Les concepts occidentaux, fondés sur la pensée grecque et la religion judéo-chrétienne, ont connu un tel succès depuis des siècles qu'il est devenu difficile de les débusquer. Les voir pour ce qu'ils sont nécessite souvent un travail considérable que seule la rencontre avec autre culture, ayant fleuri sur d'autres bases, peut permettre... 4

Robinson est pris, alors, par une sorte d'aveuglement lui empêchant la perception des valeurs propres, qu'en Angleterre, à force de coutume, il avait appris à concevoir comme universelles. C'est pour cela que Montaigne parle de l'habitude comme d'une seconde nature. La conscience que Robinson a de sa propre identité ne correspond qu'à une idée qu'il s'était construite, lui-même, à une image faite lorsqu'il faisait partie de la société britannique, qu'il considérait comme idéale, donc celle-ci était respectée par un groupe d'individus, mais en dehors de ce contexte social, il n'y avait pas d'autre individu à la respecter, sauf lui. Alors cette idée de «correction "n'existait que dans sa pensée :

...les observations que je fais ou que je crois faire sur l'autre, je les ordonne systématiquement autour de moi, le centre, le lieu géométrique de mon univers rationnel. Le gabarit, le seul modèle dont je dispose pour étalonner l'autre, c'est $\mathbf{m o i}^{5}$.

\footnotetext{
A. Buisset, * La grande image n'a pas de forme *, Le Français dans le monde, 328 (2003) 54.

5 J. F. Held et J. Maucorps, « Je et les autres : essai sur l'empathie quotidienne », cité par M. AbdallahPretceille, Vers une pédagogie intenculturelle (Paris : Anthropos, 1995) 42.
} 
Robinson craignait, également, de perdre son caractère de civilisé et devenir comme une bête. Ce souci-là, le mène à l'établissement d' une série d'ordonnances qui vont, toujours, favoriser sa position de supériorité sur l'île. Il se nomme maître de l'île et prétend tout contrôler d'après l'image de société qu'il avait quittée et qui contribue à la survie du patrimoine culturel dont il était le seul à être porteur et à assurer sa survie dans un contexte où il risquait de disparaître.

\section{Le contact sauvage-civilisé}

Le style de vie occidental véhiculé par Robinson se voit modifié par l'apparition de Vendredi, personnage qui, dès son arrivée, commence à bouleverser le mode de vie mené par le naufragé Anglais. Toutefois la rencontre entre eux se produit dans des conditions de déséquilibre, donc l'Indien contracte une sorte de dette avec son sauveur car Robinson, en plus de lui avoir sauvé la vie, lui offre un lieu où vivre dans cet espace qu'il considérait son île civilisée. Dès que Robinson prend contact avec Vendredi, il comprend que l'Indien était un être totalement différent à lui, tant dans son aspect physique que dans sa manière d'agir. C'est cette condition d'étranger qui mène Robinson à exprimer un certain rejet envers Vendredi. Cependant, il était le seul autre homme qui habitait l'île, alors, il décide inconsciemment de l'approcher à lui, de le faire un peu comme lui, et de cette manière l'accepter comme son similaire. Le sentiment de refus qui se produit chez Robinson envers son ami obéit au fait que la perception que tout individu a de la réalité est sélective. Celle-ci ne correspond qu'à ce qui s'approche des intérêts et des goûts propres, c'est-à-dire tout ce qui ressemble à soi. La différence véhiculée par Vendredi constituait une menace pour la culture de Robinson. L'Anglais a, alors, essayé de éradiquer cette différence et ainsi d'accepter son ami :

Plus la forme d'un trait culturel est « étrange », donc éloignée des formes des traits culturels de la civilisation receveuse, et plus 
son acceptation sera difficile, car c e trait culturel ne pourra être réinterprété en termes de la culture receveuse... Il n'est pas repris, mangé, digéré...6

C'est pour cela que Robinson croit avoir le droit de faire de Vendredi ce qu'il considérait le mieux pour assurer son bien-être. Il considère, également, avoir l'autorité nécessaire pour lui donner le nom qu'il croyait convenable ainsi que de le faire devenir puritain comme lui. Le maître Robinson pensait, aussi, qu'il était obligé de faire sortir son unique compagnon de son état de sauvagerie, et que celui-ci devait obéir à tout ce qu'il lui imposait. C'est à travers un modèle hé gémonique de comportements qu'il mène son ami àl'adoption de ces conduites. Decette manière Robinson assume un rôle civilisateur, il devient une sorte de bienfaiteur qui fait de Vendredi un homme civilisé. On perçoit, alors, l'optique ethnocentriste de Robinson à travers laquelle il regarde son ami et qu'on définit comme :

L'attitude d'un groupe à s'accorder une place centrale par rapport aux autres groupes, à valoriser positivement ses réalisations et particularismes, et menant à un comportement projectif à l'égard des hors-groupes qui sont interprétés à travers le mode de pensés de l'engroupe ${ }^{7}$.

C'est précisément le caractère de naturalité de la culture de départ qui assure l'ordre social établi, ainsi Robinson juge Vendredi d'après l'optique anglaise. Il ne prend pas conscience de l'existence des limites de sa culture où les règles qui la régissaient voyaient perdre sa validité car les autres cultures ont, aussi, tendance à ramener à elles ce caractère d' univer sel. Il ne considère en aucun cas que Vendredi, de la même manière que lui, avait été élevé dans une société déterminée

\footnotetext{
${ }^{6}$ R. Bastide, Anthropologie Appliquée, cité par M. Abdallah-Pretceille, Vers une pédagogie interculturelle (Paris : Anthropos, 1995) 49.

7 Cité par M. Abdallah-Pretceille, Vers une pédagogie ..., 119.
} 
qu'il tendrait aussi à l'exalter : "L'homme socialisé au sein d'une culture donnée n'est généralement pas conscient des processus cognitifs à travers lesquels il reproduit des images fausses d'autres cultures ${ }^{8}$.

Cependant l'humble Vendredi, d'après son regard naïf, ne fait qu'obéir sans comprendre même les sens de tous ces comportements inconnus :

...Mais il ne comprenait rien à toute cette organisation, à ces codes, à ces cérémonies, et même la raison d'être des champs cultivés, des bêtes domestiquées et des maisons lui échappait complètement. Robinson avait beau lui expliquer que c'était comme cela en Europe dans les pays civilisés, il ne voyait pas pourquoi il fallait faire la même chose sur l'île déserte du Pacifique...

\section{Le rapport maître-serviteur}

La dynamique entre Robinson comme être dominant et Vendredi comme dominé ne s'établit que grâce à une relation de pouvoir qui dès le premier moment se manifeste entre ces deux hommes. Robinson pour justifier d'une certaine manière son projet civilisateur, avait besoin d'un autre, spectateur et serviteur à la fois, qui pouvait approuver son œuvre. Vendredi, en tant que hôte dans cette île, accomplit, pendant les premiers jours, cette double fonction. Il manifeste son assentiment, même quand il ne comprenait rien sur ces conduites et obéit en tout à l'Anglais comme une façon de lui montrer sa gratitude. Cependant il ne tarde pas à se lasser de ces comportements qui lui étaient complètement inhabituels, en plus il regrettait sa vie antérieure, quand il était libre et il pouvait faire tout ce qu'il voulait :

Tout allait bien en apparence. L'île prospérait au soleil, avec ses cultures, ses troupeaux, ses vergers, et les maisons qui s'édifiaient

${ }^{8}$ Bastide, 120. 
de semaine en semaine. Vendredi travaillait dur, et Robinson régnait en maître. Tenn qui vieillissait faisait des siestes de plus en plus longues...

Robinson ne pouvait pas cacher sa joie d'avoir quelqu'un avec lui, mais ce qui vraiment lui rendait heureux c'était qu'il avait enfin quelqu'un dans l'île à l'aider avec les multiples taches qu'avant, il devait accomplir tout seul. Ce sentiment s'exprime à travers phrases, telles que : « il était content parce qu'il avait enfin quelqu'un à faire travailler et à qui il pouvait tout enseigner de la civilisation » et «Il s'était fait un hamac entre deux arbres où il passait tout son temps libre».

Vendredi, par contre, faisait de son mieux pour comprendre les ordres de son maître. Tous les nouveaux travaux que Robinson lui apprenait à faire ne se manifestaient que par des verbes d'action qui traduisaient l'effort qu'il devait faire pour accomplir ces activités : déchiffrer, labourer, semer, herser, faucher, moissonner, battre, moudre, pétrir, etc.

Certaines situations mettent en évidence son statut d'infériorité et de soumission envers la figure dominante de Robinson : « il était devenu le serviteur modèle ", "il assurait le service du dîner du gouverneur », «il savait raccommoder les vêtements de Robinson et cirer ses bottes », « ...Enfin il allait s'étendre sur une litière qu'il tirait contre la porte de la maison et qu'il partageait avec Tenn... », "Vendredi avait appris à ... balancer le chasse-mouches au-dessus de sa tête quand il dormait ". Lorsqu'ils décident de faire un travail ensemble, Vendredi assume toujours un rôle secondaire, tandis que Robinson prend la fonction principale : de cette manière l'Indien devient soldat quand Robinson est général, enfant de chour pour l'aider quand il priait, maçon quand il construisait, porteur quand il voyageait et rabatteur quand il chassait. 


\section{Les rituels, une forme d'homogénéisation culturelle}

Pour que le modèle culturel anglais ait pu survivre sur cette île solitaire, par-dessus la culture araucanienne, Robinson a eu besoin d'établir une série de règle d'échange et de signes comportementaux qui montrent d'une façon explicite l'appartenance à ce groupe social. C' est à travers un modèle hégémonique de comportements que l' Indien assume, petit à petit, une partie de la culture de son ami.

C'est précisément cet ensemble de règles à suivre qui permet la mise en valeur de ce que pour Robinson était la norme, étant donné qu'il agissait dès une position de supériorité, il était le seul à dire ce qui était correct et ce qui ne l'était pas. Inconsciemment, Robinson maintient une position nourrie d'ethnocentrisme par rapport à la culture de Vendredi qui souffre, alors, un processus de métissage, il doit apprendre une série de conduites qui lui étaient tout à fait nouvelles et que selon Robinson étaient considérées comme adéquates : « il était content parce qu'il avait enfin quelqu'un à faire travailler et à qui il pouvait tout enseigner de la civilisation ». Vendredi accomplit ses dispositions comme un signe de gratitude, cependant ses liens avec sa culture maternelle, étant si forts, ils ne disparaissent jamais de sa pensée donc il ne pouvait pas les oublier. Ceux-ci ne tardent pas à se manifester à nouveau :

De son côté Robinson voyait bien que Vendredi n'approuvait pas du fond du cœur cette île trop bien administrée qui était l'œuvre de sa vie. Certes Vendredi faisait de son mieux. Mais dès qu'il avait un moment de liberté, il ne faisait que des bêtises...

C'est, alors, au moyen des comportements et des attitudes, que Robinson dès sa position de supériorité, cherche à transmettre ses valeurs. Ce sont précisément ces comportements, focaliséspar Robinson comme adéquats qui produisent des rituels. Robinson cherche à établir une sorte d'uniformisation de cet individu. De cette manière Robinson 
inscrit son ami dans ce qu'il considère la norme et non plus comme sujet échappant à celle-ci. P. Charaudeau illustre très bien cette attitude manifestée par Robinson, lorsqu'il affirme que :

À force de ressemblance et d'homogénéité, l'individu tend à disparaître, son identité individuelle se fond dans une identité collective abstraite... 9

Cette métamorphose soufferte par Vendredi, est comparée avec ce qui se passe dans un chœur ou dans une manifestation où l'on n'écoute que l'ensemble des voix, toutes semblables, donc elles répètent les mêmes mots. Identifier chacune d'elles s'avère un travail tout à fait difficile !: « ...l'identification est le fait pour le sujet de s'aliéner au profit de l'objet qu'il prend en quelque sorte comme déguisement ${ }^{10}$.

De cette manière, les rituels s'inscrivent dans un schéma d'interaction fixée, dans lequel chacun fait de son mieux pour ne pas les transgresser et d'éviter, ainsi, d'être considéré par les autres (tous semblables) comme un sujet hors-norme. Cet ensemble d'habitudes obéissent à une sorte de force, qui sans être visible, a la faculté de tout contrôler, donc Robinson, avec son souci inconscient pour les respecter, assure la survie de ceux-ci. Alors, les rituels n'existent que dans la mesure où ils sont observés par un groupe d'individus. Toutefois Vendredi, même s'il accepte au premier moment de suivre toutes ces habitudes, il ne peut effacer jamais de sa pensée ce qu'il était vraiment. L'empreinte que la culture araucanienne avait laissée sur lui continue à se manifester malgré l'effort de son ami pour faire disparaître tout lien avec une culture qu'il focalisait comme inadéquate.

Il faut, alors, apprendre à respecter l'autre dans sa différence. On doit regarder tout ce qui diffère de la culture propre et qui évidemment

9 P. Charaudeau. "L'interculturel, une histoire de fou ", Dialogues et cultures, 32 (1988) : 89-97.

${ }^{10}$ C. G. Jung. Týpes psychologiques cité par M. Abdallah-Pretceille, Vers une pédagogie ..., 21. 
véhicule la différence et parfois l'opposition, d'un regard autre que celui de notre subjectivité. La voie conduisant à ce but ne peut pas être autre que celle du respect auquel on accède à travers l'éducation, une éducation du regard. Seulement l'éducation peut empêcher qu'on tende à imposer à l'autre, notre culture, sous le prétexte qu'elle est meilleure, elle permet de voir, aussi, qu'une attitude pareille ne serait qu'imposer à la fois l'avis personnel.

\section{Vendredi : source de richesse culturelle à partager}

Diversita face richezza. Proverbe corse

C'est dans l'échange avec d'autres cultures que le dialogue interculturel naît et qui contribue à amplifier les connaissances, en les enrichissant avec l'apport étranger en même temps qu'on partage le patrimoine culturel propre. Se laissant influencer par son regard stéréotypé ; à cause de l'apparence humble de Vendredi, Robinson le considère comme simple et c' est cette impression qui le fait croire que l'Indien n'avait rien à partager mais beaucoup à apprendre de lui. Cependant l'humble Vendredi, loin de rester à l'écart de la vie de Robinson, sans y exercer aucune influence, joue un rôle très important dans le rapport qui s'établit entre ces deux hommes.

Par de différentes actions cet Indien, qui avait été conçu par son ami plutôt par son apparente simplicité, lui apprend une série de nouvelles habitudes, qui ignorées par l'Anglais, ont été méprisées au premier moment, mais qui deviennent, après, tellement utiles pour lui qu'elles sont rapidement adoptées et contribuent ainsi à élargir les connaissances qu'il possédait déjà.

C'est ainsi que Vendredi, en observant le travail fait par les fourmis, a l'idée de les prendre comme moyen d'achever les restes de viande et d'assurer l'hygiène de l'île, une idée à laquelle Robinson n'avait pas pensé. Robinson, tout fier qu'il était de ses puissantes 
armes à feu, a dû reconnaître le mérite des bolas. Cette nouvelle arme, différente en tout aux siennes, était même plus efficace car elle était silencieuse, facile à rempl:acer, et cependant meurtrière. Désormais, il a dû l'admettre comme instrument de défense. Vendredi lui montre aussi un art culinaire, tout à fait nouveau, même bizarre, qui possédait un caractère spécial qui le rendait aussi bon à manger.

\section{L'ignorance source des malentendus}

On ne hait que ce que l'on ignore. Sentence du Coran

Étant donné que l'homme vit souvent enfermé dans ses propres références culturelles, il résulte difficile pour lui de percevoir et de comprendre d'autres comportements différents, voire opposés, aux siens. Lorsque Robinson et Vendredi commencent à vivre ensemble sur l'île, Robinson ne tarde pas à se rendre compte que même s'il lui avait appris à se comporter à la manière anglaise, son ami continuait à manifester des conduites qui lui résultaient tout à fait choquantes. Un jour, par exemple, l'Anglais, profondément contrarié, surprend l'Araucan en train de nourrir un horrible petit vautour avec de la viande pourrie qu'il venait de mâcher.

La perception de la différence est généralement accompagnée d'un jugement négatif. Robinson manifeste une attitude qu' on pourrait qualifier comme normale chez tous les êtres humains mais qui est, toutefois, nécessaire de corriger. Robinson assume des appréciations réductrices qui sont normales chez lui du fait qu'il porte « les lunettes déformantes » de sa propre subjectivité. Dans sa pensée ethnocentriste, Robinson ne pouvait pas accepter d'autres normes que les siennes et moins encore une conduite si répugnante pour lui comme celle du vautour. Cette attitude le mène d'abord à jeter un jugement négatif envers Vendredi, qui ne constitue qu'un mécanisme, une forme de protection dont il se sert comme d'une arme de défense contre la 
menace qui représentait pour lui la différence. Il reste pendant certains instants dans cet état où Robinson n'éprouve que du mépris pour son ami. C'est évidemment à cause de son ignorance que Robinson pense de cette manière. C'est pour cela qu'il n'ose pas aller plus loin, jusqu'à comprendre pourquoi cet être agissait de cette manière-ci :

La peur et la haine se nourrissent souvent de l'ignorance [...] L'impuissance ou l'agressivité qui sont autant de formes de l'incapacité d'affirmation de soi, également répandues dans le monde contemporain sont des revers de la même médaille, l'incapacitéà aimerl'autre, à connaître et à reconnaître l'altérité pourtant si indispensable à l'affirmation de sa propre identité ${ }^{11}$.

On croit souvent qu'un jugement négatif ne désigne que la personne ou le fait à qui il s'adresse, mais en réalité il reflète aussi celui qui le formule. Robinson essaie inconsciemment de protéger son identité, ses habitudes, de peur qu'elles puissent être mélangées avec celles de Vendredi. Il préfère ne pas la mettre à l'épreuve face à la menace qui constituait la différence représentée par les conduites désagréables de l'Indien. Robinson ne prend pas en compte que sa position parrapport au fait observé était conditionnée par sa subjectivité en oubliant que Vendredi méritait aussi un place comme la sienne :

Le regard porté d'une culture sur l'autre peut-être celui de la cécité s'il se limite à l'observation de l'objet avant de s'interroger sur la position de l'observateur... ${ }^{12}$

Comme P. Charaudeau l'affirme juger négativement c'est protéger son identité mais protéger son identité, c'est à chaque fois, perdre un peu de son identité. Avec son attitude, Robinson enferme

\footnotetext{
II S. Farandjis, Conférence : Hispanophonie et francophonie. Un nouveau dialogue, lundi 21 mars 1984, Francophonie et humanisme, débats et combats (Paris : TOUGUI, 1989) 215.

12 « D'une culture à l'autre ». Le Français dans le monde, 181 (1983) : 33.
} 
Vendredi dans un espace clos : celui du choquant et du sale, sans se rendre compte qu'à la fois il s'enfermait lui-même dans un autre espace clos qui ne lui permettait pas de connaître complètement la cause de la conduite de Vendredi. Robinson aurait fait une vérité du préjugé rejeté sur son ami, en le considérant l'être le plus sale qu'il avait connu ; s'il n'avait pas dépassé ce stade de désagrément.

Heureusement, cette gêne a été suivie par un sentiment de curiosité qui le mène à se demander pourquoi son ami faisait une telle chose. Il franchit, alors, les frontières de l'ignorance qui l'aveuglait. C'est, alors, qu'il connaît la raison de cette conduite et il arrive, ainsi, à comprendre son ami :

Robinson qui le voyait faire en eut l'estomac soulevé de dégoût, et il se sauva pour ne pas vomir. Mais au fond, il admirait les sacrifices que pouvait faire Vendredi quand il avait décidé d'aider un animal...

De cette manière, Robinson développe chez lui un certain savoir-faire lui permettant de concevoir Vendredi dès une optique autre que celle du rejet. Il le comprend et comprend à la fois sa position antérieure qui aveuglée par son ignorance ne lui permettait pas de voir la raison pour laquelle son ami agissait d'une telle manière. C'est ainsi que, sans jamais penser de la même manière que Vendredi, Robinson découvre son propre positionnement par rapport à son ami. Il apprend à le tolérer, à respecter ses habitudes même si celles-ci étaient contraires aux siennes. Alors tolérerc'est vraiment comprendre. C'est la compréhension qui est nécessaire pour arriver au respect de l'autre :

Découvrir c'est d'abord comprendre une différence. La compréhension est rare aujourd'hui entre les hommes de deux cultures contemporaines, nous ne le savons que trop, dans nos pays ou les heurts de race, pour être feutrés, masqués, n'en sont pas moins fréquents. La compréhension est aussi difficile entre 
deux cultures éloignées dans le temps [...] C'est donc d'abord par rapport à notre mentalité contemporaine qu'une culture nous apparaît comme une autre... ${ }^{13}$

C'est souvent, l'ignorance qui fait accroître les sentiments ethnocentristes et qui empêche aux individus de connaître vraiment ceux qui les entourent ainsi que de démystifier une série de stéréotypes qui sont la cause des chocs culturels si communs à nos jours :

L'ignorance de l'autre, de sa personnalité irréductible et merveilleusement propre, conduit non seulement au mépris et à la haine, mais à l'ignorance de soi, à notre propre difficulté à nous affirmer nous-mêmes, à nous aimer, à vivre notre identité irremplaçable et non assimilable à une matricule... ${ }^{14}$

\section{On ne peut pas voir l'autre qu'à travers soi, et on ne peut se voir soi-même qu'à travers l'autre}

Comprendre les autres est un idéal contradictoire : il nous demande de changer sans changer, d'être un autre tout en étant nous-mêmes. Octavio Paz

Le fait que des individus relèvent des cultures différentes, qu'ils entraînent, évidemment, des habitudes distinctes et qu'ils coexistent tout simplement, n'est pas suffisant. Certes, la diversité culturelle véhiculée par les hommes contribue à augmenter la richesse culturelle mais il est nécessaire, aussi, l'échange entre eux. Il s'agit, en fait, de dépasser le niveau de la simple coexistence, de la mosaique culturelle pour envisager les interrelations, les interconnexions.

\footnotetext{
${ }^{13}$ Cité par G. Zarate, Enseigner une culture étrangère (Paris : Hachette, 1986) 44.

${ }^{14}$ Farandjis, 217.
} 


\section{L'importance de l'Autre dans l'échange interculturel}

Le dialogue qui peut s'établir entre deux cultures suffisamment différentes est très important, parce qu'il amènerait à la connaissance puis à la compréhension réciproque. Pour $\mathrm{H}$. Besse, dans ce dialogue ce ne sont pas les cultures qui dialoguent mais les individus qui les conforment. Alors, pour que l'interaction interculturelle s'effectue vraiment, il faut absolument la présence d'un Autre, différent de soi. Sans lui, cette interaction ne pourrait pas se produire. Dès là, l'importance du rôle joué par l'Autre : «J'ai besoin de la médiation d'autrui, pour être ce que je suis ${ }^{15}$.

De la même manière qu'on peut porter un regard quelconque sur l'Autre, il constitue une source de connaissance de soi-même car lorsqu'on rejette les appréciations propres envers autrui, on livre, à la fois, une partie de soi : " Pour obtenir une vérité quelconque sur moi, il faut que je passe par l'autre. L'autre est indispensable à mon existence, aussi bien d'ailleurs qu'à la connaissance que j'ai de moi ${ }^{16}$.

Alors, l'Autre ne doit pas être focalisé en tant que sujet susceptible d'être repéré et analysé mais en tant que sujet au même niveau que Moi, car c'est lui qui regarde et non pas l'objet regardé a voir. C'est à partir de cette complémentarité, qui s'instaure entre Moi et l'Autre, que se construit l'interdépendance à laquelle vise l'approche interculturelle.

\section{Le jeu des deux mannequins}

À force d'échanger Vendredi et Robinson arrivent à se connaître réciproquement et à saisir non seulement leurs différences mais leurs propres caractéristiques. Vendredi a été le premier, qui après une longue observation de son ami, décide de construire un mannequin représentant l' Anglais et, ainsi, mener Robinson à la connaissance de lui-même. Robinson, à son tour, construit une statue de son ami et de

\footnotetext{
15 J. P. Sartre, L'être et le néant, cité par Martine Abdallah-Pretceille, « La perception ... », 40.

16 J. P. Sartre, L'existentialisme est un humanisme, cité par M. Abdallah-Pretceille "La perception ... ", 40.
} 
cette manière ils se décentrent de leur propre moi et arrivent à se connaître mutuellement d'un regard autre que le leur. Cependant ce jeu constitue à peine un préambule à l'acquisition d'une compétence culturelle qui s'est s'opérée chez ces deux individus.

\section{Le jeu du déguisement}

Il y a un autre passage dans la vie de Robinson et de Vendredi qu'on a nommé le jeu du déguisement, car chacun d'eux décide de se déguiser en l'autre, en mettant en relief le mieux qu'ils pouvaient, les caractéristiques de son compagnon. Ainsi, ces deux entités, culturellement différentes, arrivent à se mettre à la place de l'autre et, dès là, parvenir à une véritable connaissance, voire, compréhension d'elles-mêmes :

Robinson avait compris que ce jeu faisait du bien à Vendredi parce qu'il le guérissait du mauvais souvenir qu'il avait de sa vie d'esclave. Mais à lui aussi Robinson, ce jeu faisait du bien, parce qu'il avait toujours un peu de remords d'avoir été un maître dur pour Vendredi ...

\section{La décentration de Vendredi et Robinson conduit à l'objectivation}

Pendant le temps que Robinson demeure seul dans l'île, il croyait à tort se connaître lui-même. Toutefois, il ne possédait en réalité qu'une idée limitée de sa personne donc cette connaissance ne se réduisait qu'à son propre regard. C'est dès le moment où il prend contact avec Vendredi qu'un vrai dialogue entre cultures différentes s'opère. Robinson commence à saisir à partir de soi-même tout ce qui le séparait de son ami. Il le focalise, ainsi, d'après son prisme déformant qui le mène à une incompréhension donc il prenait en compte seulement son avis, l'idée qu'il s'était faite de Vendredi, pardessus ce que son ami était en réalité. Il le conçoit comme un être, porteur d'exotisme, qu'il fallait considérer comme différent, alors qu'il occupait un statut de regard au même niveau que le sien. 
Vendredi et Robinson n'arrivent à une véritable interaction que jusqu'au moment où ils prennent un statut d'égalité. Robinson laisse, alors d'être le maître duret Vendredi abandonne sa position d'infériorité d'esclave apeuré. Vendredi commence à concevoir les caractéristiques de Robinson comme des traits appartenant seulement à l'Anglais et qu'il n'était pas obligé de reproduire donc ils n'étaient pas universels. Le fait de regarder quelqu'un de différent de lui, lui produisait une sensation d'entonnement. Il passe de la simple observation, de la responsabilité qu'il croyait posséder pour faire de l'Araucan un autre comme lui et lui attribuer un statut comme le sien. À partir de là, il peut découvrir les propriétés et l' importance que son ami méritait. Alors, ce n'est qu'en établissant une comparaison entre la culturelle maternelle et l'étrangère, suivie, absolument, d'une compréhension réciproque que ces deux individus arrivent à identifier ce qui les différenciait.

\section{L'exotopie : une caractéristique que seull'autre possède par rapport $\grave{a} \mathbf{m o i}$}

Vendredi et Robinson parviennent à cette constatation grâce à une particularité que chacun d'eux possédait par rapport à l'autre. Comme tous les êtres humains, ces deux amis éprouvaient une difficulté à se connaître eux-mêmes, tels qu'ils étaient, dans leur totalité. Ils étaient incapables de se voir extérieurement et de prendre conscience de soi, du fait qu'ils étaient immergés dans leur propre personne physique. D'une certaine manière, ils étaient prisonniers dans leur propre univers rationnel. Alors, seulement une autre personne, hors eux, pouvait identifier totalement ce qui fondait leurs particularités : "Seul l'Autre peut nous voir comme nous sommes dans notre totalité grâce précisément à sa position d'extériorité ${ }^{17}$.

Vendredi et Robinson, en tant qu'autre ont réussi à cette perception simultanée grâce précisément à leur position d'extériorité dont parle M. Bakhtine et que Todorov préfère appeler exotopie, c' est-

$\overline{17}$ T. Todorov, cité par A. Séoud, Pour didactique de la littérature (Paris : Didier, 1997) 140. 
à-dire l'avantage réciproque, que par leur condition d'être autre, Robinson et Vendredi possédaient et qui leur permettait d'extraire, mutuellement, tout ce qui les singularisait. L'essentiel du jeu du déguisement réside précisément dans le fait qu'ils arrivent à se mettre en question, à se prendre eux-mêmes, en quelque sorte, comme leur propre objet :

L'important dans l'acte de compréhension, c'est pour le comprenant, sa propre exotopie dans le temps, dans l'espace, dans la culture- par rapport à ce qu' il veut comprendre. N'en vat-il pas de même pour le simple aspect extérieur de l'homme que ce dernier ne peut voir ni penser dans sa totalité, et il n'y a pas de miroir, pas de photographie qui puisse l'y aider; son aspect extérieur, seul un autre peut le capter et le comprendre, en vertu de son exotopie et du fait qu'il est un autre... ${ }^{18}$

À travers ce jeu, Robinson et Vendredi conrigent leur première perception des faits. En se déguisant comme l' autre, ces deux individus parviennent à se mettre à la place de leur partenaire et d'appréhender, ainsi, en quoi ils (en tant que leur ami) trouvaient naturel ou anormal des faits qu' ils (en tant qu'eux-mêmes) considéraient comme normaux. Chacun d'entre eux a pu parler de l'Autre comme s'il parlait de luimême, en s'identifiant l'un à l'autre. De cette manière, ils ont pu saisir leur propre expérience subjective, dès le regard d'un autre dont ils s'étaient déguisés.

À partir de ce moment-là, il s'opère chez ces deux amis, une sorte d'attitude tolérante qui leur mène au respect mutuel entre eux :

Dans le domaine de la culture, l'exotopie est le moteur le plus puissant de la compréhension. Une culture étrangère ne se révèle dans sa complétude et dans sa profondeur qu'au regard

18 Todorov, 140. 
d' une autre culture (et elle ne se livre pas dans toute sa plénitude car d'autres cultures viendront qui verront et comprendront davantage encore). Un sens se révèle dans sa profondeur pour avoir rencontré et s'être frotté à un autre sens, à un sens étranger : entre les deux s'instaure comme un dialogue qui a raison du caractère clos et univoque, inhérent au sens et à la culture pris isolément ${ }^{19}$.

\section{En guise de conclusion : L'Altérité d'après T. Todorov}

Pour T. Todorov ${ }^{20}$ la relation à l'Autre s'inscrit dans une multidimensionalité qu'il ramène à trois axes sur lesquels il situe la problématique de l'Altérité, à savoir :

1. Un axe axiologique : Il est constitué par un jugement de valeur qu' on rejette sur l' Autre. On n'entre pas encore en contact avec autrui mais on en formule une opinion sur lui. On le considère comme bon ou mauvais, on l'aime ou on ne l'aime pas, il est perçu comme égal ou inférieur par rapport à soi. Cette étape, se fait évidente lorsque Robinson et Vendredi se rencontrent pour la première fois. Robinson perçoit la différence existante entre eux et focalise son partenaire comme un être inférieur à lui.

2. Un axe praxéologique: Cet axe comporte l'action de rapprochement ou d'éloignement par rapport à l'Autre. On embrasse les valeurs de l' Autre, on s'identifie à lui ; ou bien on assimile l'Autre à soi, on lui impose l' image propre. Entre la soumission à l'autre ou la soumission de l' autre, on trouve un troisième degré qui est la neutralité ou l' indifférence. Dès le premier moment il se produit un processus de rapprochement entre l'Anglais et l'Araucan. Toutefois, ce processus connaît une lente transformation, tout au long de l'histoire. D'abord, Robinson décide d'assimiler Vendredi à soi, il lui impose sa manière de voir le monde. Après la destruction de l'île civilisée, Robinson

\footnotetext{
19 Cité par S. Amor, Pour une didactique de la littérature (Paris : Hatier, 1997) 140.

${ }^{20}$ Cité par M. Abdallah-Pretceille, Vers une pédagogie .... 44.
} 
s'identifie, petit à petit, avec la culture de Vendredi jusqu'à adopter les traits de la culture araucanienne. Le degré de neutralité ne se produit pas chez ces deux amis.

3. Un axe épistémologique: Cet axe est, peut-être, le plus important, dans la problématique de l'Altérité. À ce stade, il s'opèrent deux termes différents et décisifs dans l'accomplissement de l'objectif visé par l'approche interculturelle : on connaît ou on ignore l'identité de l'autre. Lorsque Vendredi et Robinson, au moyen du jeu du déguisement, décident de jouer chacun le rôle de l'Autre, ils arrivent à une décentration de leur propre personne qui les conduit à la connaissance tant de l'autre que d'eux-mêmes. De cette manière, ils apprennent à se respecter et à se comprendre tels qu'ils étaient. Robinson, par exemple, éprouve un changement dans le traitement que, désormais, il donne à son ami. Son tempérament, d'ailleurs dur et intransigeant donne lieu à un Robinson compréhensif et tolérant. On peut qualifier l'attitude que ces deux hommes ont acquise comme une sorte de compétence culturelle, un savoir-faire, qui leur a permis de porter un regard respectueux envers tout ce qui était diffèrent à eux. Ils ont été capables de saisir leur propre subjectivité, comme source des idées déformantes envers l' autre. De ce fait, on peut voir que la prise de conscience de sa propre subjectivité est alors la condition d'accès à l'objectivité.

On a voulu montrer, au moyen de la dynamique du jeu déguisement, comme l'éducation interculturelle se centre, aussi, dans une sorte de jeu alterné d'identification et de distanciation, dans un processus de va-et-vient entre l'Autre et Soi. De la même manière que Jacques Becquerel l'exprime : il s'agit d'un jeu finalement où le je est un autre, tout en étant mieux que jamais soi-même $e^{21}$.

...Autrefois - avant l'explosion - il ne pouvait pas y avoir de dispute entre eux. Robinson était le maître. Vendredi n'avait

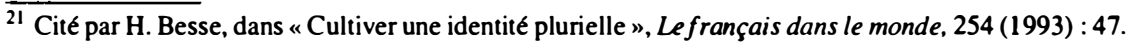


qu'à obéir. Robinson pouvait réprimander, ou même battre Vendredi. Maintenant Vendredi était libre. Il était l'égal de Robinson...

Ce roman constitue, alors, un excellent espace capable de susciter la réflexion interculturelle autour des deux entités culturellement distinctes. Cette histoire met en rapport deux univers complètement différents, voire opposées mais qui, malgré leur différence, ont réussi, par le biais du respect à une connaissance et à une compréhension mutuelle. La différence est, de ce point de vue, un aspect indispensable dans toute société donc c'est précisément ce facteur qui conditionne, dans le roman, l'enrichissement culturel grâce à la diversité que Vendredi et Robinson entraînent comme trait identificateur de leur culture d'origine:

C'est bien là le merveilleux de cette histoire. Les deux volets de Robinson sur son île, Avant-Vendredi, Avec-Vendredi, s'articulant parfaitement l'un sur l' autre, le drame de la solitude s'exhalant dans un appel à un compagnon, puis se trouvant soudain étouffé, suffoqué, par la survenue d'un compagnon en effet, mais inattendu, surprenant, une déception affreuse -un nègre !- contenant pourtant toutes les promesses d'une relance prodigieuse de l'aventure et de l'invention. Car il est clair qu'un compagnon tel que Robinson l'attendait -un autre Anglais, un autre Robinson-aurait fait retomber l' aventure assez platement ${ }^{22}$.

${ }_{22}$ M. Tournier, Vendredi ou la vie saurage (Paris : Gallimard, 1997) 186. 